\section{Moving towards democratic classrooms for the students at the University of Toronto}

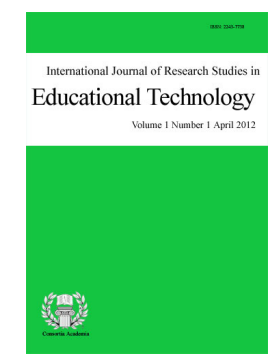

ISSN: $2243-7738$ Online ISSN: 2243-7746

OPEN ACCESS

\title{
Abstract
}

The Centre for Teaching Support \& Innovation (CTSI), University of Toronto (UT) has been organizing teaching assistance teaching sessions called "Teaching Assistants Training Program" (TATP) for the Teaching Assistants and the Course Instructors of the UT in the Roberts Library since 2002 for the promotion of democratic classroom learning to UT students. The UT Scarborough campus and UT Mississauga campus also facilitate some teaching learning workshops for TAs and for course instructors too. The idea behind this TAs teaching training program is to prepare TAs and students to be democratic in their practices of teachings and learning. As well to facilitate peer teaching and peer learning process among students. In fall 2011, CTSI facilitated seventeen workshops for UT graduate students and Teaching Assistants (TAs). The author attended eleven of them. Both TAs and graduate students of UT attended CTSI workshops from September 2011 to November 2011. Average numbers of participants were 30. This presents the basis of the author's personal experiences that he gathered from the TATP workshops, classrooms experiences from different universities (York University and UT) and literature review on teaching learning. TATP workshops discussions and exercises were in the form of group conversations and dialogue among workshop facilitators and workshop participants for collaborative learning among them, TA and the graduate students. The author gained democratic effective teaching techniques from these workshops sessions. The democratic discussions and exercises in the sessions led to TAs and graduate students' mutual growth, appreciation, deliberation, hope and autonomy. The author found many mature students, TAs (aged more than 45 years) and students with physical disabilities that attended these workshops had different learning styles than the younger students. Hence CTSI could include sessions on adult learning teaching strategies for older adult students and students with disabilities. Moreover, CTSI could include follow up on post-workshop TA performance in the classrooms.

Keywords: democratic classrooms; effective lesson planning; microteaching; peer teaching 


\section{Moving towards democratic classrooms for the students at the University of Toronto}

\section{Introduction}

The Centre for Teaching Support \& Innovation (CTSI) at the University of Toronto (UT) is looking to bring dynamism to classroom teaching and e-learning. The CTSI at UT has organized trainings and workshops for TAs and course instructors on all three UT campuses in Toronto since 2002. It orients TAs to democratic teaching strategies, transforms the perceptions of students in the classrooms and helps UT students to exchange their views, express their ideas and think critically. This ultimately leads to freedom of speech, transformative learning, and an increase in the critical reflections of students in the class. The University of Toronto believes democratic classroom settings and group discussions can generate flexible learning and develop intellectual scholarship and innovation. The CTSI training allows TAs to learn how to help students feel a sense of ownership over class discussions.

Through the Teaching Assistants' Training Program housed within CTSI of UT, the center provides workshops for TAs and course instructors for the promotion of democratic classroom learning. The CTSI intends to prepare graduate and undergraduate students working as TAs to be successful in their teaching careers and to create a peer-based support network. The CTSI teaching workshops and training sessions provide opportunities to TAs and students for situational analysis and specific contextual analysis, and helps students to critically look at theories, concepts and ideas to understand pedagogical development, civic development and the application of their knowledge and skills to real learning situations and practical life.

Through the CTSI workshops, the centre tries to blend theory, content, experience, methodology, and assessment to equip students with critical thinking skills, the reflective practice of teaching and learning, and transformative democratic teaching and learning. The idea behind the training is to prepare TAs and students to be democratic in their practices of teachings and learning. This process aims to build the capacity to act and promote cross-cultural learning opportunities and the application of social sciences, humanities and science faculties' values, ethics, sustainable identities and social justice perspectives. It aims to also build intercultural skills, and a sense of responsibility. Moreover, the CTSI objectives are links between students' own lives and TAs' lives and help students to challenge injustice in solidarity with those who are suffering throughout the world.

\subsection{Significance of democratic teaching and learning}

Nowadays, democratic classroom teaching and learning is important because it is a way of seeing students, teachers and others' social reality. Democratic classroom teaching and learning has been given many names by different scholars including collaborative learning, group work and study teams, cooperative learning, collective learning, teaching communities, peer teaching, peer learning, reciprocal learning, team learning, study circles, study groups, and work groups etc. All these teaching and learning styles can be facilitated through formal group learning work and informal group learning work.

Teaching means helping students learn and grow their academic skills. Hence TAs should have clear and concise knowledge about the course materials, course objectives and outcomes. The CTSI has been trying to make UT classrooms translate the university's educational mission, objective and values to its students to address political, social, economic, and environmental problems. It tries to prepare its students to utilize their life-transforming experiences and develop a sense of responsibility to act so that the students can implement their classroom knowledge in their educational life, practical life and job life.

\subsection{Center for Teaching Support \& Innovations (CTSI) trainings}


The CTSI provides teaching and learning support for the TAs of the UT for their teaching pedagogy development and familiarizes them with different democratic teaching techniques and instructional technologies. Its Teaching Assistant's Training Program (TATP) offers two types of professional development sessions offered on a volunteer basis: Teaching Fundamentals Certificate and Advanced University Teaching Preparation Certificate which is for the UT graduate students. The Teaching Fundamentals (TF) certificate requires TAs/graduate students to participate in six workshops. The Advanced University Teaching Preparation Certificate (AUTP) requires attendance at 10 workshops, completing one practicum component and submitting a teaching dossier and written reflections. The goals of the TA certificate programs are: to analyze the essentials of effective classroom communication, establish a supportive classroom environment, analyze the classroom audience for the purpose of preparing and delivering effective lectures, develop necessary skills for leading classroom discussion, develop course lesson planning, prepare, administer and debrief exam tools and mechanisms, facilitate and manage culturally diverse classrooms and orient TAs to grading and the assessment of student assignments. The programs also covers ground rules for class discussion, strategies for responding to challenging questions and situations, dealing with silent situations, silent students, moving from abstract to concrete descriptions and examples, moving from particular experiences to structural analysis and dealing with the roles and responsibilities of TAs. These workshops help TAs exchange ideas, observe and broaden their repertoire of ways of interacting with students in the classroom. TAs can then synthesize and apply training materials in their own classroom.

\subsection{Workshops of the Center for Teaching Support \& Innovation (CTSI) for the TAs}

The CTSI offers the TATP workshops in fall, winter and spring workshop series every year. In the fall term of 2011, the following sessions were offered as part of the TAPA workshop series on the St. George campus: ${ }^{1}$

$>\quad$ Your first class

$>$ Icebreakers: getting to know your class

$>$ Elements of effective lesson planning

$>$ Responding to student diversity

$>$ Supporting and developing blackboard techniques

$>$ Blackboard grade centre (Blackboard is a learning management system broadly used at UT)

$>$ PowerPoint and classroom presentations

Dreat expectations: a workshop on marking papers in humanities and social sciences

$>$ Dealing with students in difficulty

$>$ Fostering academic integrity

$>\quad$ What do I do if I don't know the answers?

$>$ Making the syllabus work for TAs and the students

$>$ Questioning techniques

$>$ Demystifying library research

$>$ Preparing the teaching dossier

$>$ Syllabus clinic: designing TAs' Syllabus as a learning tool

$>$ Microteaching sessions

The author below describes his observations and experiences based on his participation in CTSI website workshop series:

$>$ Great expectations: In this workshop, TAs learns and delves into some of the complexities of marking students' written work in humanities and social science courses. The session discusses the grading of papers and standards and how marking can help students' learning as well as strategies to make

\footnotetext{
${ }^{1}$ The author extracted lists of workshops and their descriptions from CTSI's upcoming workshops at http://www.teaching.utoronto.ca/about_ctsi/servicesexpertise/ctsi- workshops/workshops.htm retrieved dated December 19, 2011.
} 
marking time-efficient and fair. The session also addresses how to resolve some typical grading problems.

D Dealing with students in difficulty: This workshop focuses on how to identify, engage, refer and manage students who may be challenging. Students, who are withdrawn, distressed, demanding or who present unusual requests or situations, including crisis situations, often need special support and/or attention. Instructors mentioned that some special strategies and resources needed to address these situations. For example, if any students are behind in understanding the concepts/discussions, the TAs must notice it and help them with care to update their understandings.

> Fostering academic integrity: This section discusses UT's various academic policies and advises on issues of academic integrity and how to tactfully deal with such situations. It also looked at the ethical principles of UT in university teaching and common teaching mistakes etc., as well as helping students to avoid plagiarism. If a student copies any portion of statements or copies any text from any source without proper citation when preparing a written reflection or a scholarly paper, the student is considered to be misrepresenting her or himself. To check plagiarism, do a lexis/nexis/triton (plagiarism detect e-tools) on the topic to find any relevant news articles the student might have used. The TATP workshop advice students not to use open source journals on the Internet, Wikipedia, Blogs, etc. as they are not scholarly research sources and are not acceptable for course assignment grading. This will be discussed later in this paper.

$>$ PowerPoint and classroom presentations: This beginner level, hands-on workshop introduces participants to the basics of using PowerPoint. Additionally, it explores some of the resources that can be drawn on to effectively design and add to classroom presentations. It helps TAs develop PowerPoint skills like creating a presentation template, designing slides, viewing modes and adding graphics, video, hyperlinks and more. The following resources are given in the classes for review: Flickr.com and Creative Commons images, MIT open courseware and Slideshare.

D Demystifying library research: In this session, UT librarians share their top picks of tools, services, and research guides, and work with TAs to strategize responses to typical undergraduate research and essay problems.

> Preparing teaching dossiers: The author was familiar with the concept "teaching dossiers" in the workshop series. The teaching dossier is a comprehensive record of teaching activities and accomplishments that is required in applications for permanent positions at the Universities across North America. This session reviews the elements of a successful teaching dossier and discusses how to use it as a framework for setting goals for future professional development. In the CTSI WebPages it can be found in details. (Centre for Teaching Support and Innovation (CTSI, 2011). Web source: CSTI. http://www.teaching.utoronto.ca/about_ctsi.htm). The author is thinking about becoming involved in the teaching profession and will create a teaching dossier that might help him access teaching profession in coming days.

$>\quad$ What do I do if I don't know the answer? This workshop explores strategies TAs can use to continue to encourage questions and discussion even when they are unsure about their own expertise in the subject matter. This session also touches on how to approach the Course Supervisor to request support or clarification around subject matter the TAs are not yet totally confident teaching.

> Making TAs' syllabi work for them and for their students: The course syllabus is the primary means of communicating course objectives and instructor expectations. A well-crafted syllabus ensures that students understand the essential requirements for participating and succeeding in a course. In this workshop, participants evaluate sample course syllabi and identify the components of a clear and meaningful syllabus. They also learn how syllabi can help guide student learning and serve as an 
Moving towards democratic classrooms for the students at the University of Toronto

effective course management tool. Attendees receive useful take-away resources and guidelines that help them prepare their own course documents.

D Syllabus clinic: (Re) Designing your syllabus as a learning tool: The syllabus clinic sessions evaluate course syllabi that are prepared by TAs. Here syllabus clinic participants work in small groups to review and assess each other's syllabi.

Microteaching sessions: The microteaching session involves a small group of peer instructors teaching short lessons in front of each other in order to gain feedback on their teaching. In these sessions, a group of TAs and an instructor get together in a classroom. Each TA presents a short (5-7 minutes) lesson on a topic he or she has taught or will be teaching. The lesson is videotaped. After each lesson, the instructor and other TAs offer constructive feedback. The microteaching sessions allow TAs to practice their teaching in a low-risk situation and to receive immediate feedback on their teaching from a single mentor and from colleagues.

The University of Toronto Mississauga Campus (UTM) conducts hands-on sessions for TAs for supporting and developing their blackboard teachings. It also offers Grade Center trainings that focus on how to post learning materials, how to access the Grade Center and create columns, enter grades and view how they are displayed to students, how to organize the Grade Center, weight grades and calculation totals, how to download and Upload the TAs' Grade Center. It also explores some Grade Center features such as grade history and grouping students by using Smart Views, using communication tools such as announcements and emails, and managing student marks using the Grade Center.

\section{Literature review}

\subsection{TA development and discussion teaching}

Brookfield and Preskill (1999) in their book "Discussion as a way of teaching: tools and techniques for democratic classrooms" suggested fifteen purposes for discussions: becoming aware of diversity, appreciating ambiguity and complexity, challenging assumptions, listening attentively and respectfully, acknowledging continuing differences, increasing intellectual agility, seeing connections, respecting experiences, practicing democratic habits, creating knowledge together, communicating together, learning collaboratively, broadening understanding and empathy, synthesizing, integrating and transforming ideas and actions (p. 22). One of their suggestions is to bring newspaper clips related to the course materials in order to stimulate discussion. This can make the classroom a mini-democracy and facilitate discussion, dialogue and conversation in a playful way where all students express their opinions within the framework of the course themes. These mini-democratic class discussions could benefit students (1) critical understanding of the course topics, (2) enhance their self-awareness and their capacity for critique, and (3) foster a diversity of opinions. This democratic discussion generates openness to free thinking and creates a flexible environment for constructing arguments and counterarguments among students.

This critical discussion class room environment allows students to connect course topics with contemporary private and public issues that are oppressive and dehumanizing in society. Democratic discussion and practice in the classroom led to students' mutual growth, appreciation, deliberation, hope and autonomy, increased pluralistic thinking and building and developing mutual relationships and trust among students. In order to make excellent, effective and equal participatory discussions, Brookfield and Preskill (1999) gave suggestions to prepare the students before the discussion begins. The suggestions are: (1) Ensure early and equal access to relevant course material for the students, (2) Use lectures to model democratic talk, (3) Use critical incident questionnaires, (4) TAs could help students generate ground rules for the discussion and (5) TAs should clarify their expectations to avoid tangents outside of the course themes (p. 43-60). Good discussions don't just happen. They are the result of thoughtful planning and consistent modeling by the TAs. 
TAs also needs to supervise students' activities and pay attention to class lectures and group discussions and mentor their skills development in the classrooms. Vagenas (1992) indicates that the mentoring approach to TA training is not only about conducting TA workshops; rather it includes supervising and professionally supporting TAs. Therefore, it is also important to develop managerial relationships and to focus on instructional tasks, and develop interpersonal relationships in order to guide the students. The researcher found the TATP workshops sessions were striving to disseminate the above literatures' ideal themes and suggestions among the TA participants of the workshops for the wellbeing of the undergraduate students, University of Toronto. Furthermore, Nyquist and Wulff (1996) in their paper "The ultimate challenge of TA training in communication" identified some challenges to and indicators of TA development. TAs should be aware about how students relate to them and how they are responding to course themes. Some TAs finds it challenging to lead discussions and to properly evaluate and grade students' works. They could overcome such challenges if they accommodate diverse students; know various types of learning styles and differences. For these accomplishments, they need to be analytical and reflective, and consult with their peers about key situations and issues.

Curzen and Damour (2000) mention that many TAs have painful experiences, but they are surviving, improving them, and become brilliant teachers. They learn from their mistakes and are continuously looking for further improvement. After the first class, TAs should reflect among themselves about the class and what went right and what went badly. They should analyze why classes went badly, see it as a learning experience and fix the mistakes in the next class. While, Brookfield and Preskill (1999) mentioned that TAs shouldn't discourage or ignore someone who cannot articulate himself/herself well, rather they should encourage the person's contributions related to the course materials. TAs should be mindful about who has spoken and who has not and should make all students aware of their responsibility to be prepared to bring ideas/thoughts to the classroom. The democratic classroom sharpens their awareness and increases their sensitivities. However, if TAs are not well-equipped to facilitate democratic discussion in classrooms, the discussions could turn negative or a few students may dominate the class. TAs should also be aware of the pitfalls of lengthy and irrelevant discussions in the classrooms. Hence careful classroom planning is important.

The next section shows the discussion of the different types of teaching group techniques that the author has experienced in CTSI-TAPA workshops sessions and other classroom sessions at York University, University of Toronto and Social Economy Centre workshops. The TAPA democratic teaching techniques generate dynamism in the democratic TAPA workshop sessions through two-way interactions among TAs and workshops facilitators that the author has learned from the TAPA sessions.

\subsection{Types of group discussions in the classrooms}

On CTSI web eleven types of group teaching techniques in the classrooms are identified. The techniques are: buzz groups, poster tour, rotating stations, snowballing, cocktail party, jigsaw, critical debate, and line up or "stand where you stand," dramatizing discussion, drawing discussion and mail/online discussions.

$>\quad$ In the buzz group discussions, students form pairs or groups of four or five to discuss issues from their course material for 5-15 minutes.

$>\quad$ The poster tour groups are new interesting groups formed by students in the class where students tour the classroom and they discuss subjects on the flip charts or posters displayed on the classroom walls. The rotating station discussions are good icebreakers for students in the first class.

$>\quad$ In the Social Economy Centre (SEC) workshops, facilitators facilitating the snowballing discussions where students are rotating and progressively expanding their groups. Here students prepare a question alone, then discuss it with their group partners, then join another pairs to form new groups of four, then eight, and so on until the whole class has been brought together.

$>\quad$ The cocktail party is very popular among the students especially in the Ontario Institute for Studies in 
Education (OISE) classrooms. In the cocktail party, either students or teachers voluntarily bring food to the classroom and make the classroom discussions very lively and engaging.

$>\quad$ In the jigsaw discussion, students become "experts" by researching a topic, and explain it to other students in class. For a class of 25 , about five topics would be assigned to students and each student would choose one to research and a group of students who have chosen the same topic gather to raise questions in the same group and explore areas of understanding/misunderstanding. Then groups take turns to lead group discussion.

$>$ In the feminist critical class debate sessions at (OISE) and Social work courses at the Centennial College, Toronto, the author found that students take an informal vote on a contentious issue. They are then asked to form a debating team favoring the opposite side to the one they voted for. Each team elects a spokesperson and the debate ensues. Debate style discussion is effective because students can argue the theories, concepts, reading materials and encourage students to challenge each other's arguments and their own thinking about controversial issues in a coherent and democratic way. The debate discussion encourages students to make thoughtful arguments for their positions. Debates are good ways for students to hear both sides of arguments.

$>$ The author has familiar with another interesting democratic group discussion concept "Line-up or Stand Where You Stand". It is a class discussion technique for debating a controversial issue that I have learned from Peace Education Class at OISE in September 2011. In the class, a line of masking tape is placed on the floor, with each end of the line representing a position on a contentious issue. Students are asked to stand at the point in the line that represents their opinions. In these strategic discussions, the professor/TA provides a statement of a position and puts up four signs around the room, "strongly agree," "agree," "disagree," and "strongly disagree." Students write down their views and then choose a position accordingly.

$>$ The author has experienced another interesting workshop discussion technique from the theatre based non-violence communication workshop session in August 2011. Here the facilitator organizes a dramatic discussion session where workshop participants are invited to report their discussions of an issue through some sort of role playing (theatre/drama). Students take the form of a role play of the "right" and "wrong" way to approach an issue.

$>$ The author has experienced another group discussion technique called "Drawing Discussion". In drawing discussion of technique sessions, students are supplied with flip chart sheets, pens, rulers, scissors and tape and asked to provide a visual representation of the important themes in their discussions.

$>$ The teller program group discussion gives students opportunity to get classmates ideas about their different components training, workshops and group meeting sessions like icebreaking, descriptions of their activities/works, physical settings, experiences from the workshops, training sessions, group discussions feedback collected from their participants, pattern of interactions with classmates and support services from the organizations. In this session Shanthuja; a participant of a peace building workshop mentioned that she has facilitated a HIV-Safe Sex workshop in the North York Community Center in Toronto. Many young participate in her workshop. She received feedback from the participants that helped her improve her next workshops. The author learnt about classroom facilitation mechanics from the teller program discussion. The author facilitated many workshops in Africa where many adult women and men had participated. The workshops settings were informal in rural areas. The author gathered experience from them regarding their needs, their perception of life and livelihood, and survival with substance production.

$>\quad$ The author studied the course "program planning and evaluation" at the Ontario Institute for Studies 
in Education (OISE). In this course, the teacher displayed play card sequence demonstration on "program planning and evaluation design", which was very interesting. In this play card demonstration, classmates put cards in different sequences. At the end, classmates discovered that planning steps could be either linear, curve, and circular even some steps run parallel. This important exercise technique was full of fun. This group exercise has helped the author to learn customized planning and evaluation different steps to use in different settings, context and programs. This program planning and evaluation play card session could be one of the most exciting techniques for adult learners too.

> Blackboard/Mail/Online Discussion: The author has learned about it from TAPA workshop sessions. Moreover, the author took two courses that were taught online by the University of Toronto in 2009-2010. One course was 'Training and Evaluation' at OISE and the other was 'Human Resource Development' at the Rotman School of Management. Here students are mostly asked to comment on topic online on weekly basis. In these two courses, the writer sent his questions and answers through emails and blackboard threads each week that were assigned in the courses. The writer sent his opinions online on a weekly basis. The author wrote his weekly discussions/opinions on the reading materials and posted them on the blackboard for online discussion. Like him, many other students initiated questions and new topics for discussion on the blackboards. The teachers evaluated students online/blackboard questions/answers and graded students' works online. Like other students, the author enjoyed these online discussions. This is an IT-based student group discussion among course students to exchange their course themes through blackboard threads, emails and blogs.

In addition to the workshops described above, CTSI provides one-on-one counseling services to TAs and the course instructors if they seek it out. The CTSI training also assists TAs to behave objectively in the classrooms. However, it would be important to include a workshop on how TAs could develop interpersonal communication skills. Nyquist and Wulff (1996) suggest that TAs need to take a softer approach to students. They urge TAs not to treat students as experimental subjects rather to understand students' intellectual abilities and facilitate students' collaborative effort in the classrooms for students' effective learning. For guiding, planning, conducting and evaluating discussions, TAs can use the above group discussion learning strategies/techniques and can offer a variety of practical ideas, tools and techniques for creating demographic classrooms and encouraging students' practical participation in the classroom discussions.

\section{Feedback on TATP workshops}

The current paper provides feedback/opinions on TATP workshops. The above-stated group discussion techniques can be adapted to a wide range of teaching classroom discussion settings. These democratic teaching exercises, case studies of successful practices and examples can be useful to students for their participation in the learning discussion process. These teaching techniques cultivate and nurture democratic dispositions and discussion habits in students. Hence adaptable, practical and clearly articulated teaching strategies are more important for effective learning. The author attended eleven sessions (Sept. - Nov. 2011) of the TATP workshops conducted by CTSI where he has learned and gained personal experience in wonderful democratic teaching and learning strategies from these workshops. CTSI have also used documentary films in a few workshops, but TAs shall get more ideas if the CTSI workshops could include more films to model teaching styles that facilitate student learning.

The CTSI workshops had encouraged lively two-way interactions among the workshop facilitators and the TA participants. The author found some TATP workshops facilitators were experienced to facilitate two ways democratic discussions in the workshops that of the CTSI that facilitated in fall 2011. They helped solve many teaching related practice issues through group discussions and reporting strategies among TAs. Although the writer has not yet been involved in teaching, he has experience with TAs from his undergraduate classes at York University. For example, during his undergraduate courses, if he asked TAs to clarify questions, many TAs did 
not directly answer, rather they encouraged him to discuss his questions with his classmates. Sometimes they referred him to the course materials. In undergraduate studies at York University, the author had found many TAs write class discussion summaries on the blackboards. Many of them present course themes through PowerPoint slides and display films in the classes. Their email communications and Blackboard discussions improved class room discourse and benefit student learning. They made lively discussions/ exchanges between teacher (facilitator) and students (participants). However, many TAs leave limited time for discussion in the classrooms because of time limit. However, the CTSI workshops help the TAs follow democratic teaching strategies, a fulfilling a need for greater interaction in university classrooms.

The author noticed that the CTSI workshops have helped many TAs to change their authoritative role with students to a friendly democratic one in the classroom. He had observed that many TAs in the CTSI workshops takes on an authoritative role in CTSI group discussions, but after the workshops, they identify their limitations and become open, flexible and democratic with their students in the classrooms. For example, three TAs (graduate students of OISE) participated in the TATP workshops in fall 2011. The author got some feedback from them. They mentioned that they learn lots about democratic class discussions facilitation processes from the TATP workshops and they are trying to play democratic facilitators' role in their assigned undergraduate classes at UT. This reflects positive impact of the TATP workshops upon the TA participants.

Moreover, the author observed that many of the CTSI workshop facilitators are more listeners than talkers and slow down their talking speeds in the workshops. However, the IT instructors of the CTSI workshops instruct and navigate IT menus very quickly. This was difficult for some TAs including the author to follow. Furthermore, the IT instructors sometimes had authoritative attitudes and fewer listeners in their sessions. As the author is a slow learner, hence he was unable to follow the IT speedy instructions and menu navigations of the blackboard sessions, grade centre sessions, and PowerPoint and e-resource session. Therefore, it is essential that CTSI could look at how its instructors are meeting the needs of the students, particularly those with special needs. The CTSI could arrange one-on-one sessions with students who have learning disabilities.

The author also found many mature TAs had attended the CTSI workshops, which had different learning styles than the young TAs. Hence, CTSI could include one session on adult teaching strategies for older participants. In the adult learning strategy workshop, it is better that the TAs talk less, but facilitate adult students' conversations.

Discussion in the form of conversation and dialogue could blend different learning ideas. This dialogue process could facilitate democratic discussion, diversity of intellectual agility and endorse collaborative learning and the generation of collective knowledge among students. Sometimes the conversation strategies engage unprepared students to participate in the conversation and understand the concepts and assignments. In such situations, teachers can ask different types of questions that can lead to discussion among students in the class and improve their ability to listen carefully.

\subsection{Some challenges for TAs}

The most important thing is that TAs needs to address the possibility for tension arising from ethnic, cultural, social class and gender differences. TAs should be attentive to handling sensitive discussions including issues like race, gender, sexuality, sexual orientation, class and political topics. They need to review how to balance the voices of students, while still preserving the moral, political and pedagogic integrity of discussion. TAs could raised these points at the beginning of the semester in the classrooms and advise students they should be respectful to all other students irrespective to ethnic, cultural, social class and gender differences of their classmates. To avoid delicate situations arising from these sensitive discussions, it is better to lay ground rules about class norms. It is important to make a safe space for everyone to discuss through ground rules. In every class, TAs could wrap up the class discussion for the day, requiring summarizing skills. It is also good to bring a guest speaker on specific topics to share their experiences and skills with students. 
"The Great Expectations" is a TATP workshop on Marking Papers in Humanities \& Social Sciences facilitated in October 18, 2011. In this workshop facilitators facilitated marking exercise and discussed about grade complaints that are common among a few students. Some students think their TA give them lower grades than other TAs. Hence TAs should be open-minded, calm and rational when discussing the grades of the students. Moreover, TAs self revisions are important. Moreover they can consult with their course instructors about the actual markings complain if any raised by students. Sometimes TAs are strict in their marking because of the marking policies of the course. If TAs are unable to explain the grade adequately to the student, it is better refer student to their respective course instructors. Sometimes TAs faces antagonistic students. Moreover, students may make comments or write papers that are more antagonistic than thoughtful. Hence in such situations, it is better for TAs should not immediately become defensive rather to hear students' perspective. The facilitators' advice TAs could deal with the students in constructive ways like voicing their intellectual disagreements in such a way that maintain a productive learning environment. In the TATP marking exercise sessions, the author found different TAs graded different grades (varied from B to A+) to the same exam paper. In practical situations, grading variations might happen by different graders; however, a specific guideline for a course might reduce these markings variations.

In the workshops especially the "marking papers" session, facilitator discussed details about feedback on student assignments. The literature mentions that it is important that TAs remind students about the due dates two weeks before and the week before the assignment is due. After receiving assignments, TAs should carefully read over the assignments, grading them with comments on each assignment, highlighting both the strong and weak points of the assignments, also pointing out spelling and grammar errors. TAs could write their comments on the paper or type comments on a separate page(s) and attach these page(s) with the respective students' assignments. Curzen and Damoiur (2000) suggest there is no need for comments or questions in the margins, if a paragraph has been well written. TAs should provide their comments/feedback at the end of the papers. Throughout the whole course, TAs should monitor students' progress/regress in their different assignments. If it is possible, it is helpful to allow students to revise their papers for further improvement. If any questions arise about the grading of the assignments, TAs could help students learn how their assignment could be improved next time.

\subsection{Template questions for facilitating group discussions in the classrooms}

The author learned some common template questions for facilitating group discussions in the classrooms from the TATP workshops like "Responding to student diversity", "Dealing with students in difficulty", "What do I do if I don't know the answer and responding to student diversity etc." Moreover the author read many TAs training books and articles where he has found template questions for facilitating group discussions in the classrooms. For example, Brookfield and Preskill (1999) suggested every lecture should begin with one or more questions that the teacher is trying to answer and that there should be a period of silence after raising the question. To elicit participatory feedback from the student about the lectures, TAs could ask questions like the following: what are the important points that have been made in the lecture so far? What question would they like to have answered regarding the topic of the lecture today? What is the most obscure or ambiguous topic in the lecture? What action taken in the classroom this week did TAs find most affirming or helpful? Which discussion most confused students? What surprised students most about the class this week? TAs could ask students what they would have liked to have covered in the course on the last day. This question helps instructors to redesign the course or to add new topics in the course. The most important thing is to keep the discussion going through questioning, listening and responding.

As TAs are working for the courses managed by the instructors, TAs should frequently interact, report problems, provide feedback about the class experiences and seek advice from the instructors. Curzen and Damour (2000) provide some tips on how to run student discussions in class. Class discussions can start through asking questions about students' opinions about the reading materials, films shown in class, or specific issue. Examples of questions are the following: What do you think of the readings? How and why are they relevant to 
the course objectives and goals? What are the pros and cons of the theories? What is the authors' point in the essays? What are points the authors use to support their argument. Questions keep students on track and involved in discussions on the course material. Students also enjoy viewing video presentations in the class. TAs should make advance arrangement for TVs, VCR, YouTube and videos. After a video presentation, TAs could collect feedback from the students and ask students to relate the video's themes to the course objectives. Moreover, TAs need to be attentive to recording students grades in their e-resources and developing grade books online. The Blackboard grade centre workshop facilitators described and taught navigation ways to the TAs participants on how they could record students grades in the Blackboard e-resources.

In the TATP workshops, TAs mentioned that usually they are assisting the professors, holding office hours/tutoring, leading discussion in the tutorial classes, conducting quizzes, conducting exams, evaluating and grading students' assignments, and marking and recording all grading, which are their jobs. Course instructors can learn from TAs to minimize ambiguity and use opportunities to get feedback about the lectures from the TAs although TAs are assisting the course instructors to administer the course. TAs need to emphasize the importance of linking discussion to specific goals and motivate students to participate in the tutorial discussions. The TAs could read the course outlines as well as refer the course outlines at different times during the course and refer students about the objectives/ goals of the course so that students can be attentive and concentrate their discussions/assignments around the course learning outcomes. Moreover, TAs should be clear to the students at the beginning of the course about relevant grading procedures and policies. It is better if TAs could attend all the lectures of the course instructor and relate tutorial class discussions with the class lectures.

\subsection{TA Manual}

A TA manual could help TAs get everything together in one-place to get information quickly and to deal with course management. The University of California Los Angeles (UCLA) has a TA training manual that consists of formal training, apprenticeship and situation-based components (Source: UCLA, 2011-2012 webpage). The UC training includes TA orientation, a TA handbook, departmental and university workshops, seminars and a pro-seminar. Apprenticeship occurs in two ways: (1) TAs spends one quarter of their teaching time assisting experienced instructors. The second means of apprenticeship is a mentoring program that assigns a faculty member to work closely with each TA during their first two quarters of teaching. The UT could also develop a one-stop information TA handbook that may include descriptions of the different style of democratic teaching, TA relationships and their responsibilities to the basic course directors and office staff. The handbook could be developed through regular discussion in classrooms.

The CTSI organized a national/international conference on the training of TAs in May 2011 that enhanced opportunities for learning and for professional contacts among TAs and TA trainers. Although CTSI could organize course specific training for TAs, it can organize weekly meetings, a forum for brainstorming ideas, learning about classroom preparation, timing and developing teaching strategies. These meetings could provide mental and emotional preparation to TAs for classes. All these efforts together strengthen TAs professional mentoring system.

It is good for TAs to have interactions with the students. These interactions could help students to feel more at ease with the TAs and to help students know what to look for in assignments, class presentations and group discussions. TAs can develop a weekly class preparation plan, prioritizing goals, lesson plans, class discussion plans and class lecture plans. Teaching plans could have combinations of lectures, discussions and two-way information exchange in the classes. Hence it is better to write the main notes on the board when conducting classes. Well, this actually depends quite a bit on what the course instructor wants and the subject being taught.

\subsection{Teaching students with learning disabilities}

At the beginning of the course, TAs should inform the class if anyone needs special accommodations, that 
certain supports are available for students' with disabilities. Students with disabilities often need extra time for writing their assignments and they may require take their exams in a separate room. For example, the author found the York University Accessibility Services for Students with Disabilities (YUASSD) arranged written exams separately in its YUASSD computer lab. The author had three classmates at the undergraduate level at York University their exams in the accessibility services computer room where they used special computers (bigger screen and bigger keyboard). The YUASD computers have special software (Brail, Kurzweil). Students with physical disabilities were given extra one hour for their exams. The exam was managed by separate invigilators. In the TATP workshop "What do I don't If I know the Answer?" the facilitator also mentioned TAs should be aware about students with disabilities issues and provide them information.

However, if students have other personal problems like depression, eating disorders or drug or alcohol abuse, it is not the TA's job to diagnose or treat the problems. The TATP facilitators narrated how to manage disruptive or dominating students in the classrooms. They suggested some strategies to handle such abnormal situations. Facilitators stated that it is good that TAs are aware of how the personal problems of students could be interfering with their performance in the class. In such case, Curzan and Damour (2000) suggest that TAs could inform students of resources like free mental health services and academic counseling. While TAs can try to accommodate and empathize with students if they seem upset, penitent or frantic, it does not mean TAs do some favor to these types of students. However, TAs should not approach students about problems unless TAs are quite sure that something is going wrong for those students outside of the classroom. TAs could have a conversation with them in the departmental rooms' in their office hours. The author thinks it might be challenge to handle such critical situation by new TAs. Hence TAs may identify disruptive students at the beginning, face the situation diplomatically and inform the instructor. They should know emergency contact number and report it to the concern security personnel if necessary. The TATP facilitators provided UT emergency contact telephone numbers to the workshop participants.

\section{Conclusions}

All these processes described above not only enhance students' epistemological development, but also help them apply what they are learning to real-life settings. This happens if TAs are able to facilitate two-way dynamic interactions in their teaching sessions. Through this process of creating a collaborative learning environment, the CTSI wants TAs to translate high impact learning into reflective practice.

The CTSI workshops are integral to developing a democratic teaching environment among TAs, teachers and students of UT. Through the CTSI democratic learning sessions, UT TAs are not only able to gain cognitive development, rather they develop their intrapersonal skills. It is important for graduate students (TAs) to internalize, integrate, conceptualize, intervene and apply their classroom knowledge outside of classroom settings and laboratories that could helps them mature intellectually and allows for in-depth critical analysis drawing on their intercultural, intergenerational, interracial, inter-gender, and intersexual and intersectionality orientations in their practical life.

The CTSI TA workshops definitely contribute to these learning pedagogies. However, the CTSI could follow up on post-workshop TA performances in the actual classrooms. As students' numbers are increasing at the undergraduate level and graduate level at the UT and many graduate students will be in teaching jobs in future, hence the CTSI training is very important for development of TAs in teaching professions and for democratic learning environment in the classrooms.

\section{References:}

Ash, S. L., Clayton, P. H., \& Atkinson, M. P. (2005). Integrating reflection and assessment to capture and improve student learning. Michigan Journal of Community Service Learning, 11(2), 49-60.

Barkley, E. F., Cross, K. P., \& Major, C. H. (2005). Collaborative learning techniques: A handbook for college 
faculty. San Francisco: Jossey-Bass.

Brookfield, S., \& Preskill, S. (1999). Discussion as a way of teaching: Tools and techniques for democratic classrooms. San Francisco: Jossey- Brass Publishers

Brigham, M. (2011). Creating a global citizen and assessing outcomes. Journal of Global Citizenship \& Equity Education, 1(1), 15-43.

Centre for Teaching Support and Innovation (CTSI). (2011). About CSTI. Retrieved January 5, 2012, from http://www.teaching.utoronto.ca/about_ctsi.htm

Curzan, A., \& Damour, L. (2000). First day to final grade: A graduate Student's guide to teaching. Michigan: The University of Michigan Press.

Civikly, J. M. \& Hidalgo, R. (1992). TA training as professional mentoring. In J. D. Nyquist \& Wulff, D. H. (Eds.), Preparing teaching assistants for instructional roles: Supervising TAs in communication. Virginia: SCA Publication.

Nyquist, J. D., \& Wulff, D. H. (1996). Working effectively with graduate assistants. London: Sage Publication.

Williams, K. J. (1992). Three innovations in TA training. In J. D. Nyquist \& Wulff, D. H. (Eds.), Preparing teaching assistants for instructional roles: Supervising TAs in communication. Virginia: SCA Publication.

Ministry of Training, Colleges and Universities (MTCU). (2005). Framework for programs of instruction. Retrieved April 6, 2011 from http://www.accc.ca/ftp/es-ce/MTCUCollegeFramework.pdf

Nyquist, J. D., \& Wulff, D. H. (1992). The ultimate challenge of TA training in communication. In J. D. Nyquist \& Wulff, D. H. (Eds.), Preparing teaching assistants for instructional roles: Supervising TAs in communication. Virginia: SCA Publication.

Vagenas, R. (1992). A mentoring approach to TA training. In J. D. Nyquist \& Wulff, D. H. (Eds.), Preparing teaching assistants for instructional roles: Supervising TAs in communication. Virginia: SCA Publication.

Smith, R. A. (1997). Making teaching count in Canadian higher education: Developing a national agenda. Teaching and Learning in Higher Education, 21, 1-10.

Zundel, P., \& Deane, P. (2010). It's time to transform undergraduate education. University Affairs Newsletter. Retrieved April 5, 2011 from http://www.universityaffairs.ca/its-time-to-transform-undergraduate-education.aspx

University of California, Los Angeles. (2012). The TA handbook 2011-2012. Retrieved January 13, 2011 from http://www.oid.ucla.edu/publications/tahandbook 
Rouf, K. A. 